University of Nebraska - Lincoln

DigitalCommons@University of Nebraska - Lincoln

\title{
Simultaneous observations of mesospheric gravity waves and sprites generated by a midwestern thunderstorm
}

\author{
D. D. Sentman \\ University of Alaska \\ E. M. Wescott \\ University of Alaska \\ R. H. Picard \\ Air Force Research Laboratory \\ J. R. Winick \\ Air Force Research Laboratory \\ H. C. Stenbaek-Nielsen \\ Air Force Research Laboratory
}

See next page for additional authors

Follow this and additional works at: https://digitalcommons.unl.edu/usafresearch

Part of the Aerospace Engineering Commons

Sentman, D. D.; Wescott, E. M.; Picard, R. H.; Winick, J. R.; Stenbaek-Nielsen, H. C.; Dewan, E. M.; Moudry, D. R.; São Sabbas, F. T.; Heavner, M. J.; and Morrill, J., "Simultaneous observations of mesospheric gravity waves and sprites generated by a midwestern thunderstorm" (2003). U.S. Air Force Research. 16.

https://digitalcommons.unl.edu/usafresearch/16

This Article is brought to you for free and open access by the U.S. Department of Defense at DigitalCommons@University of Nebraska - Lincoln. It has been accepted for inclusion in U.S. Air Force Research by an authorized administrator of DigitalCommons@University of Nebraska - Lincoln. 


\section{Authors}

D. D. Sentman, E. M. Wescott, R. H. Picard, J. R. Winick, H. C. Stenbaek-Nielsen, E. M. Dewan, D. R. Moudry, F. T. São Sabbas, M. J. Heavner, and J. Morrill 


\title{
Simultaneous observations of mesospheric gravity waves and sprites generated by a midwestern thunderstorm
}

\author{
D.D. Sentman ${ }^{\mathrm{a}, *}$, E.M. Wescott ${ }^{\mathrm{a}}$, R.H. Picard ${ }^{\mathrm{b}}$, J.R. Winick ${ }^{\mathrm{b}}$, H.C. Stenbaek-Nielsen ${ }^{\mathrm{b}}$, \\ E.M. Dewan ${ }^{\text {b }, ~ D . R . ~ M o u d r y ~}{ }^{\mathrm{a}}$, F.T. São Sabbas ${ }^{\mathrm{a}}$, M.J. Heavner ${ }^{\mathrm{c}}$, J. Morrill ${ }^{\mathrm{d}}$ \\ ${ }^{a}$ University of Alaska, Geophysical Institute, Fairbanks, AK 99775, USA \\ ${ }^{\mathrm{b}}$ Air Force Research Laboratory, Space Vehicles Directorate, Hanscom AFB, MA, USA \\ ${ }^{\mathrm{c}}$ Los Alamos National Laboratory, NIS-1, Los Alamos, NM, USA \\ ${ }^{\mathrm{d}}$ Naval Research Laboratory, E.O. Hulburt Center for Space Research, Washington, DC, USA
}

\begin{abstract}
The present report investigates using simultaneous observations of coincident gravity waves and sprites to establish an upper limit on sprite-associated thermal energy deposition in the mesosphere. The University of Alaska operated a variety of optical imagers and photometers at two ground sites in support of the NASA Sprites99 balloon campaign. One site was atop a US Forest Service lookout tower on Bear Mt. in the Black Hills, in western South Dakota. On the night of 18 August 1999 we obtained from this site simultaneous images of sprites and $\mathrm{OH}$ airglow modulated by gravity waves emanating from a very active sprite producing thunderstorm over Nebraska, to the Southeast of Bear Mt. Using $25 \mathrm{~s}$ exposures with a bare CCD camera equipped with a red filter, we were able to coincidentally record both short duration $(<10 \mathrm{~ms})$ but bright $(>3 \mathrm{MR})$ $\mathrm{N}_{2}$ 1PG red emissions from sprites and much weaker $(\sim 1 \mathrm{kR})$, but persistent, $\mathrm{OH}$ Meinel nightglow emissions. A time lapse movie created from images revealed short period, complete $360^{\circ}$ concentric wave structures emanating radially outward from a central excitation region directly above the storm. During the initial stages of the storm outwardly expanding waves possessed a period of $\tau \approx 10 \mathrm{~min}$ and wavelength $\lambda \approx 50 \mathrm{~km}$. Over a $1 \mathrm{~h}$ interval the waves gradually changed to longer period $\tau \approx 11 \mathrm{~min}$ and shorter wavelength $\lambda \approx 40 \mathrm{~km}$. Over the full $2 \mathrm{~h}$ observation time, about two dozen bright sprites generated by the underlying thunderstorm were recorded near the center of the outwardly radiating gravity wave pattern. No distinctive $\mathrm{OH}$ brightness signatures uniquely associated with the sprites were detected at the level of $2 \%$ of the ambient background brightness, establishing an associated upper limit of approximately $\Delta T \lesssim 0.5 \mathrm{~K}$ for a neutral temperature perturbation over the volume of the sprites. The corresponding total thermal energy deposited by the sprite is bounded by these measurements to be less than $\sim 1$ GJ. This value is well above the total energy deposited into the medium by the sprite, estimated by several independent methods to be on the order of $\sim 1-10 \mathrm{MJ}$.
\end{abstract}

(c) 2003 Elsevier Science Ltd. All rights reserved.

Keywords: Sprites; Gravity waves; Lightning

\section{Introduction}

Sprites are transient (several to 10's of ms) optical emissions generated within the mesosphere $(50-90 \mathrm{~km})$ by large lightning discharges (e.g., Sentman and Wescott, 1993; Lyons, 1994; Fukunishi et al., 1996; cf. Sentman,

\footnotetext{
* Corresponding author. Tel.: +1-907-474-6442; fax: +1-907474-7290.

E-mail address: dsentman@gi.alaska.edu (D.D. Sentman).
}

1998). Several mechanisms have been proposed for sprite production (see review by Rowland, 1998), all based on impact excitation of ambient molecular species by electrons accelerated in transient mesospheric electric fields following a lightning discharge in the underlying thunderstorm. The most generally accepted mechanism is the quasi-electrostatic mechanism of Pasko et al. (1997a). Imaging and photometric measurements reveal a continuous range of sprite brightnesses, from a few tens of $\mathrm{kR}$ for small events to several MR for the brightest forms (Moudry et al., 2003). Studies of 
sprite occurrence over thunderstorms in the central US show that sprites tend to occur predominantly over the trailing stratoform regions of large mesoscale convective systems (MCSs) of size greater than $\sim 20,000 \mathrm{~km}^{2}$ (Lyons, 1996), although studies in other regions of the world show them also to occur over smaller storms (Fukunishi et al., 1999; Su et al., 2002).

Spectroscopic studies have shown the optical emissions of sprites are predominantly from the red $\mathrm{N}_{2} B^{3} \Pi_{g}\left(v^{\prime}\right) \rightarrow$ $A^{3} \Sigma_{u}^{+}\left(v^{\prime \prime}\right) 1$ PG (First Positive) bands of neutral molecular nitrogen (Mende et al., 1995; Hampton et al., 1996; Heavner et al., 2000). Weak ion signatures have been reported in both red $\mathrm{N}_{2}^{+}\left(A^{2} \Pi \rightarrow X^{2} \Sigma_{g}^{+}\right)$Meinel emissions (Bucsela et al., 1998; Morrill et al., 1998) and blue $\mathrm{N}_{2}^{+}\left(B^{2} \Sigma_{u}^{+} \rightarrow X^{2} \Sigma_{g}^{+}\right)$ 1NG (First Negative) emissions (Armstrong et al., 1998; Suszcynsky et al., 1998; Takahashi et al., 1998; Armstrong et al., 2000). Electron impact excitation and ionization of $\mathrm{O}_{2}$ are also believed to occur (Pasko et al., 1997a), but collisional quenching suppresses optical emissions from these species. The characteristic electron energy of a few eV leading to the $\mathrm{N}_{2}$ 1PG emissions also leads to excitation of rotational and vibrational states of the ambient species, within both the observed transition states of $\mathrm{N}_{2}$ (Cartwright, 1978; Green et al., 1996) and a larger group of quenched states of both $\mathrm{N}_{2}$ and $\mathrm{O}_{2}$ (Morrill et al., 2002; Bucsela et al., 2003). Thus, while the $\mathrm{N}_{2} 1 \mathrm{PG}$ emissions constitute the bulk of the optical energy observed, they are likely to represent only a small fraction of the total energy deposited in the mesosphere at the location of a sprite.

Establishing the total energy deposited by sprites in the middle and upper atmosphere is important within the context of the overall energy budget of this region, including inputs from other external sources, such as by solar EUV or auroral particle precipitation from above, or by gravity waves from below. Stenbaek-Nielsen et al. (2000) have presented observations suggesting local composition effects in sprite tendril formation, but the relative importance of large scale composition or dynamical effects induced in the embedding medium depends significantly on the total amount of energy available compared to other sources. In situ diagnosis of the energy deposition associated with the electrical perturbation of sprites is hampered by the difficulty of placing instruments within the discharge region at the time of the events. One is thus led to consider signatures of secondary effects produced in the medium by the electrical perturbation that produces sprites, such as the ambient airglow layers in the upper atmosphere.

Sprites typically extend to altitudes of $85-90 \mathrm{~km}$ (Sentman et al., 1995), and thus penetrate into the airglow regions maintained in the mesosphere by a balance of various chemical and transport processes. The visible volume of large sprites often exceeds $10^{4} \mathrm{~km}^{3}$ for large events (Sentman and Wescott, 1993). Their duration is short (few ms), so thermal energy deposited in the neutral atmosphere within a sprite would be expected to produce an impulsive pressure pulse that propagates laterally outward as an acous- tic wave or gravity wave. Pasko et al. (1998) have estimated the neutral heating perturbation within streamer structures to be $\Delta T / T \sim 0.2-2 \%$ at altitudes at altitudes of 50 $-60 \mathrm{~km}$. High resolution imaging of sprite structures have revealed them to be composed of multiple thin streamers (Gerken et al., 2000), so the "filling factor", or the fractional volume occupied by streamers within the body of a sprite, is very small, estimated to be $\sim 10^{-4}-10^{-3}$. The associated neutral temperature perturbation averaged over the full body of the sprite is then $(0.3-3 \mathrm{~K}) \times\left(10^{-4}\right.$ $\left.10^{-3}\right) \sim 3 \times 10^{-5}-3 \times 10^{-2} \mathrm{~K}$. For a sprite volume of $10^{12} \mathrm{~m}^{3}$ and neutral density of $2 \times 10^{20} / \mathrm{m}^{3}$ at $85 \mathrm{~km}$, this corresponds to a total energy range $\sim 0.1-10 \mathrm{MJ}$. Other work based on scaling of observed optical emission line ratios has suggested that the total energy deposited in the mesosphere by sprites could be as large as $\sim 1$ GJ (Heavner et al., 2000).

Given the large range of uncertainty in the energy deposition, spanning some 4 orders of magnitude, it was deemed worthwhile to search for a possible temperature perturbation signature by way of correlated effects on the nightglow emissions (Sentman et al., 1999), both as a way to narrow the range of uncertainty and to clarify the nature of possible secondary effects on airglow processes. Positive detection of sprite-correlated nightglow pulses would provide a method for indirectly determining the underlying thermal energy deposition associated with the sprites, as well as other related processes, while a negative result would permit establishing an upper limit on the energy deposition.

Rowland et al. (1996) and Pasko et al. (1997a, b) have considered the converse problem, that of the manner in which effects of gravity waves on the background might play a role in determining the ignition location or structure of sprites. Siefring et al. (1998) have presented examples of apparent close association between sprites and short period gravity wave structures observed during one of the EXL98 aircraft flights, suggesting a possible linkage between the two.

In Section 2 the linkage between gravity waves and $\mathrm{OH}$ emissions is reviewed. Section 3 describes the experiment that yielded the observations, which are presented in Section 4. Section 5 describes the analysis of the observations, their interpretation in terms $\mathrm{OH}$ Meinel emissions, and the corresponding energy limits on sprite deposition derived from these observations. A short discussion on related issues is given in Section 6. Results and some additional comments about the observations conclude the paper in Section 7.

\section{OH chemistry and wave dynamics background}

Of particular interest to this study is the $\mathrm{OH}$ nightglow layer located at $\sim 85 \mathrm{~km}$, first reported by Meinel (1950). The production of vibrationally excited hydroxyl $\mathrm{OH}(v)$ in the nighttime mesosphere is due to a set of coupled chemiluminescent reactions whose basic processes involve ozone 
destruction by atomic hydrogen (Bates and Nicolet, 1950). The set of reactions needed to explain observations has subsequently been expanded to include other odd oxygen and odd hydrogen species (Makhlouf et al., 1995),

$$
\begin{aligned}
\mathrm{H}+\mathrm{O}_{3} & \rightarrow \mathrm{OH}(v \leqslant 9)+\mathrm{O}_{2}, \\
k_{1} & =1.4 \times 10^{-10} \mathrm{e}^{-470 / T}, \\
\mathrm{O}+\mathrm{HO}_{2} & \rightarrow \mathrm{OH}(v \leqslant 6)+\mathrm{O}_{2}, \\
k_{2} & =3 \times 10^{-11}, \\
\mathrm{O}+\mathrm{O}_{2} & +M \rightarrow \mathrm{O}_{3}+M, \\
k_{3} & =6 \times 10^{-34}(300 / T)^{2.3}, \\
\mathrm{H}+\mathrm{O}_{2} & +M \rightarrow \mathrm{HO}_{2}+M, \\
k_{4} & =5.7 \times 10^{-32}(300 / T)^{1.6}, \\
\mathrm{OH}(v)+\mathrm{O} \rightarrow \mathrm{H}+\mathrm{O}_{2} & k_{5}=a_{5}(v) \times 10^{-11}, a_{5}(v=0)=3.9, \\
a_{5}(v & =1)=10.5, a_{5}(v>1)=25,
\end{aligned}
$$

where $T$ is the ambient neutral temperature in $K$, and $k_{1} \ldots k_{5}$ are rate coefficients in $\mathrm{cm}^{3} / \mathrm{s}$ for two-body reactions, and $\mathrm{cm}^{6} / \mathrm{s}$ for three-body reactions involving a third species $M$, either $\mathrm{N}_{2}$ or $\mathrm{O}_{2}$. For the first two reactions the total rate coefficient for production of all vibrational states $v$ is listed. Near the mesopause the neutral temperature is $T \sim 170 \mathrm{~K}$. The vibrationally excited states can be quenched by collision with major species or chemically by the $\mathrm{OH}(v)+\mathrm{O}$ reaction above, but the major loss over most of the region of interest is by radiation,

$\mathrm{OH}(v) \rightarrow \mathrm{OH}(v-\Delta v)+h v, \quad A_{v, v-\Delta v}$,

where $A_{v, v-\Delta v}$ is the Einstein coefficient for spontaneous emission, $v=1, \ldots, 9$, and $0<\Delta v \leqslant v$. The observed radiance $I_{v, v-\Delta v}$ from the vibrational level $v$ to level $v-\Delta v$ transition is then the integral of the volume emission rate $A_{v, v-\Delta v}[\mathrm{OH}(v)]$ along the line-of-sight, where $[\mathrm{OH}(v)]$ is the density of species $\mathrm{OH}$ in vibrational state $v$. The nighttime airglow, or nightglow, generated by these reactions produces bright emissions (hundreds of $\mathrm{kR}$ ) from the $\mathrm{OH}\left(X^{2} \Pi, \Delta v=2\right)$ first-overtone Meinel sequences at wavelengths $1.4-2.2 \mu \mathrm{m}$, with the total intensity of all emission sequences exceeding several MR (Chamberlain, 1961).

Gravity waves produced by convective core motions of vigorous thunderstorms propagate into the high atmosphere and constitute a major source of mechanical energy and momentum into this region from below (Swenson and Liu, 1998). Among other effects, these thunderstorm-generated gravity waves can modulate the optical emissions in the nightglow layer (Krassovsky, 1972) that are detectable from the ground (e.g. Taylor and Hapgood, 1988; Taylor and Hill, 1991; Turnbull and Lowe, 1991) and from orbiting imaging platforms (Dewan et al., 1998; Picard et al., 1998). The emission intensity of the $\mathrm{OH}$ nightglow is sensitively dependent on small wave-induced temperature fluctuations (Makhlouf et al., 1995) and readily responds to thunderstorm-generated gravity wave temperature fluctuations to produce brightness variations such as reported by Taylor et al. (1995).

The effect of a gravity wave on the $\mathrm{OH}$ nightglow emissions is determined by computing the linear response of the coupled set of Eqs. (1) and $\left(1^{\prime}\right)$ to a small temperature perturbation $\Delta T$. Because the rate coefficients in the reactions above possess different temperature dependencies, the steady-state emissivity is also temperature dependent. The differential response of the $\mathrm{OH}$ Meinel Emission intensities $I_{\mathrm{OH}}$ to small temperature perturbations was first studied by Krassovsky (1972) and may be expressed in terms of the differential temperature perturbation as

$\frac{\mathrm{d} I_{\mathrm{OH}}}{I_{\mathrm{OH}}} \approx \eta \frac{\mathrm{d} T}{T}$,

where $\eta$ is a factor that depends on wave parameters including frequency and phase speed. For mesosphere conditions and the set of reactions in Eqs. (1) and $\left(1^{\prime}\right)$ above, the factor $\eta$ ranges from $|\eta|=10$ for $c_{\mathrm{ph}}=40 \mathrm{~m} / \mathrm{s}$ to $|\eta|=$ 5 for $c_{\mathrm{ph}}=140 \mathrm{~m} / \mathrm{s}$ (Makhlouf et al., 1995). Hence, a small temperature change produces a correlated $\mathrm{OH}$ optical emissivity response amplified by a factor of 5-10. To scale optical emission variations to the underlying temperature effects requires knowledge of the amplitude and phase of the $\eta$ parameter, which can be determined from the measurable parameters of the wave modulating the $\mathrm{OH}$ emission.

In the present study we searched for transient, in situ heating effects at the mesopause produced by sprites through their effects on the modulation of the nocturnal $\mathrm{OH}$ airglow emissions, similar to the effects produced by gravity wave modulation of the $\mathrm{OH}$ emissions. While making the measurements of sprites above a very vigorous thunderstorm we unexpectedly captured a well-defined example of an outwardly expanding, gravity wave driven concentric ripple pattern in $\mathrm{OH}$ emissions driven by the thunderstorm, similar to effects first reported by Taylor and Hapgood (1988), and further described by Dewan et al. (1998). The wavelength and period extracted from these narrow band waves provided a key parameter for characterizing the perturbation response of $\mathrm{OH}$ needed to evaluate the sprite heating parameters.

\section{Experiment}

Observations were performed during August 1999 as part of the NASA Sprites99 campaign (Bering et al., 1999; Bering et al., 2002) at a US Forest Service fire observation tower on Bear Mt. (latitude $43.88 \mathrm{~N}$, longitude $103.75 \mathrm{~W}$, altitude $2150 \mathrm{~m}$ ), located in the Black Hills near the city of Custer, South Dakota. The observing camera was a Photometrics SenSys Model $400768 \times 512$ pixel $\times 12$ bit unintensified CCD system equipped with a Kinoptic 


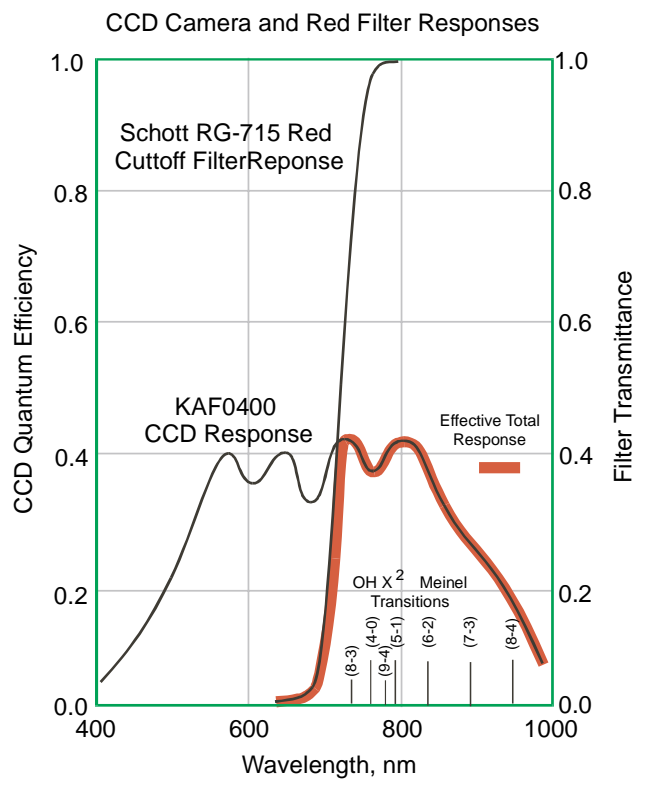

Fig. 1. CCD and cutoff filter responses as functions of wavelength, and the combined response pass band. Also shown are locations of the band origins of the $\mathrm{OH}\left(X^{2} \Pi\right) \Delta v=4,5$ Meinel sequences within the combined response pass band.

$5.7 \mathrm{~mm} f / 1.8$ TEGEA wide angle lens. The CCD-lens combination provided a $60^{\circ} \mathrm{H} \times 40^{\circ} \mathrm{V}$ degree field of view. We used a Schott RG-715 715-nm red filter to pass a selected band of wavelengths in the NIR region of the spectrum. When combined with the camera response, the camera-filter combination (NIR CCD) possessed an overall optical pass band of 715-920 nm FWHM. Fig. 1 shows the respective response functions of the camera-filter system.

The $\mathrm{OH}$ nightglow emissions we observed are not the brightest among the several types of nocturnal skyglow. As noted above, the brightest emissions occur in the short-wave infrared (SWIR) $\left(X^{2} \Pi, \Delta v=2\right)$ first-overtone Meinel sequences 1.4-2.2 $\mu \mathrm{m}$. However, the $\mathrm{OH}$ intensities are significant (several tens $\mathrm{kR}$ ) in the shorter wavelength 700-900 nm near-infrared (NIR) $\mathrm{OH}\left(X^{2} \Pi, \Delta v=3,4,5\right)$ Meinel sequences (Yee et al., 1991) and are the emissions reported here. The CCD cooling requirements for detection of the NIR emissions are much less stringent than for SWIR, and make it possible to use standard CCD technology operating near the upper limits of the camera wavelength sensitivity. Thus, one may use bare (unintensified) CCD technology for sufficiently long exposure times (tens of seconds) (e.g., Taylor and Hill, 1991; Taylor et al., 1991a, b) with a relatively modest $\left(T \sim 0^{\circ} \mathrm{C}\right)$ amount of cooling and is the method we used for the present observations.

Table 1 lists the principal OH Meinel bands and their locations within the overall instrument pass band 700-900 nm. The pass band included the $\mathrm{N}_{2}\left(B^{3} \Pi_{g} \rightarrow A^{3} \Sigma_{u}^{+}\right) \Delta v=2$ $(740-780 \mathrm{~nm})$ and $\Delta v=1(850-900 \mathrm{~nm})$ sequences, so
Table 1

OH $\left(X^{2} \Pi\right)$ Meinel vibration-rotation bands $720<\lambda<1000 \mathrm{~nm}$

\begin{tabular}{lll}
\hline Band & $\begin{array}{l}\lambda(\mathrm{nm}) \\
(\mathrm{Q}-\text { branch })\end{array}$ & $\begin{array}{l}\text { Relative } \\
\text { intensity }\end{array}$ \\
\hline$\Delta v=3$ & & 2 \\
$(3-0)$ & 966 & \\
$\Delta v=4$ & $(\mathrm{R}-$ branch $)$ & \\
$(9-5)$ & & 3 \\
$(8-4)$ & 1000 & 8 \\
$(7-3)$ & 940 & 7 \\
$(6-2)$ & 883 & 5 \\
$(5-1)$ & 834 & 6 \\
$(4-0)$ & 792 & 3 \\
$\Delta v=5$ & 753 & \\
$(9-4)$ & & 10 \\
$(8-3)$ & 776 & 6 \\
\hline
\end{tabular}

Source: Pearse and Gaydon (1976).

the system was also sensitive to the sprite $1 \mathrm{PG}$ emissions. Hence, we were able to image both $\mathrm{OH}$ nightglow emissions and sprites simultaneously.

The operational mode of the present experiment involved performing $25 \mathrm{~s}$ exposures followed by a $5 \mathrm{~s}$ period to transfer the digital images from the camera to hard disk, yielding an effective image frame rate of $1 / 30$ fps. The camera was connected via an interface card to a desktop computer. Image acquisition and readout were controlled with a custom script running within the main Photometrics camera control program. The computer system timer, updated continuously over the Internet to maintain $100 \mathrm{~ms}$ accuracy absolute, was used to synchronize image acquisition. The resultant set of images was processed off line for histogram equalization using an average histogram for the entire sequence as a reference, and combined into a digital video clip for further analysis and presentation. A separate intensified CCD (ICCD) television system was also operated during the campaign to obtain images of many of the brighter sprites that registered in the NIR images.

\section{Observations}

On the night of 18 August 1999 over a $2 \mathrm{~h}$ interval we obtained very clear images of both gravity wave modulated nightglow emissions and sprites associated with a very intense thunderstorm over Nebraska. The thunderstorm is shown in GOES infrared imagery with overlaid lightning strike information in Fig. 2. Over the $3 \mathrm{~h}$ period 0400-0700 UT, the center of storm convection and lightning activity moved approximately $200 \mathrm{~km}$ from south-central Nebraska to eastern Nebraska/Iowa at an average speed of about 60 $-70 \mathrm{~km} / \mathrm{h}(17-19 \mathrm{~m} / \mathrm{s})$. This storm track was roughly orthogonal to the observing line of sight, which approximately preserved the distance to the storm during the observing interval. Observing conditions were close to ideal, with a 

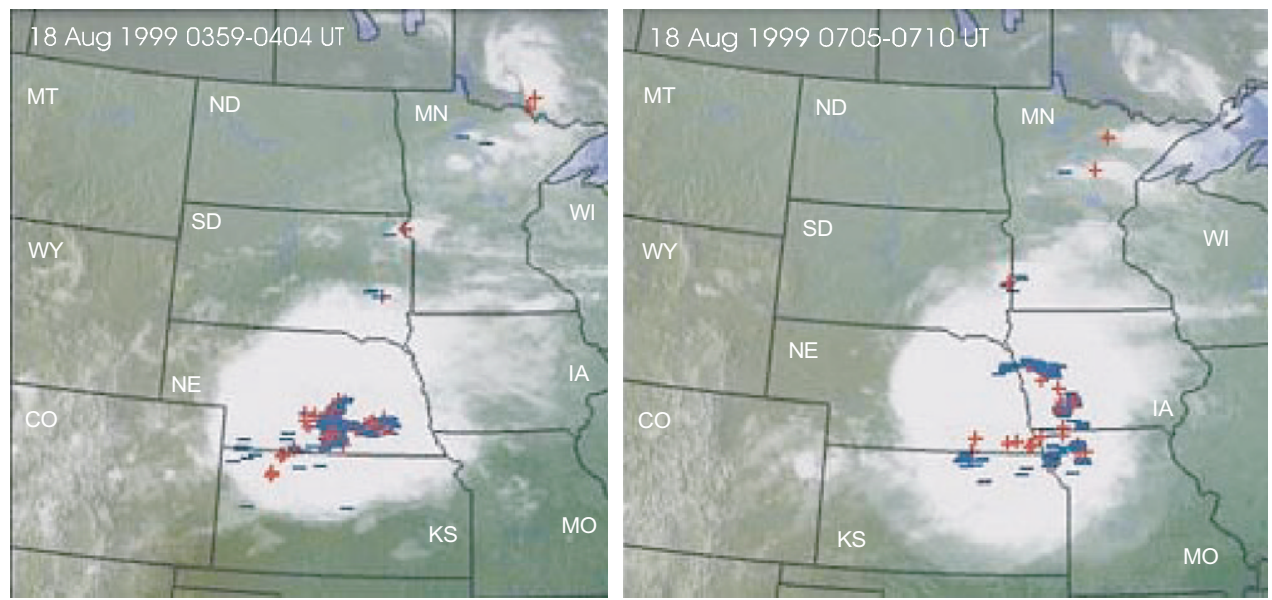

Fig. 2. GOES-8 10-12 $\mu \mathrm{m}$ temperature maps of a thunderstorm over central Nebraska-western Iowa and associated lightning studied during the night of 18 August 1999. The two maps show the same storm separated by three hours. Superimposed atop the maps are 5 min averages of lightning activity, where blue denotes negative CG (cloud-to-ground) lightning, and red denotes positive CG lightning. Adapted from near-real time maps downloaded from http://www.weather.com.



Fig. 3. Outwardly expanding concentric ripples observed in $\mathrm{OH}$ emissions using $25 \mathrm{~s}$ time exposure in the NIR. The field of view is approximately $60 \mathrm{H} \times 40 \mathrm{~V}$ deg. The dashed lines labeled "analysis strip" delineate the region used to create Fig. 5 . The city lights of Custer, SD and lights from the Crazy Horse Monument are labeled at the bottom of the large plot. The stars in the figure are used to fix the viewing direction using the Smithsonian Star Catalog. The sprite on the main image is shown in the inset in more detail (recorded by a separate ICCD camera).

clear sky above the observing site permitting visual access to nightglow and sprite activity in the mesosphere above the thunderstorm.

Fig. 3 shows one of the NIR CCD images obtained during the observation interval. In the foreground near the bottom of the large image are seen the lights of the city of Custer, SD, and to the left the display lights of the Crazy Horse Monument. Left lower center there is a large sprite, shown in high resolution as a cutout from the ICCD TV camera. The stars are clearly visible at the top of the figure. The hazy elliptical features in the lower central portion of the figure labeled as "Concentric Expanding Gravity Wave Ripples" are the 


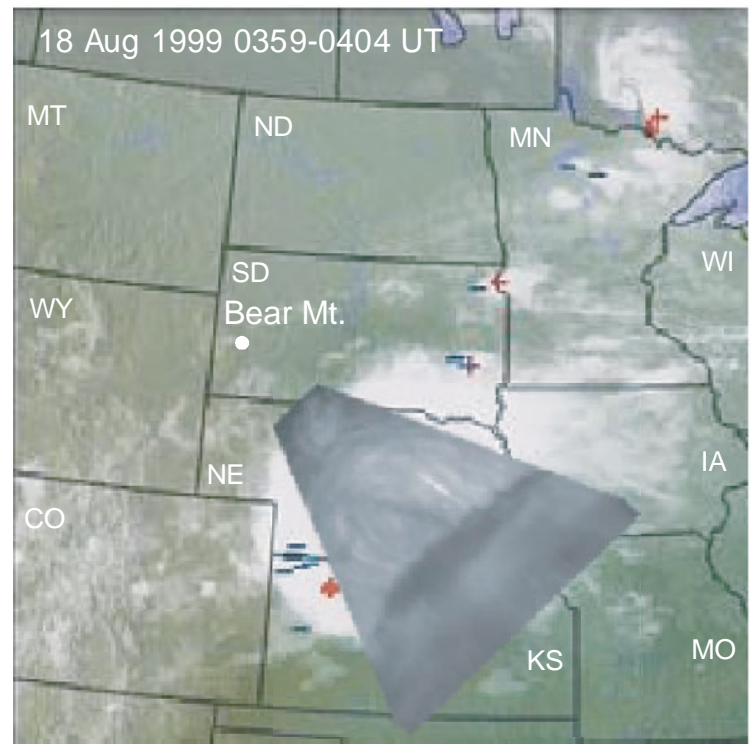

Fig. 4. GOES-8 weather image with image of Fig. 3 mapped to the $85 \mathrm{~km}$ tangent surface and overlaid on top of it. The outward expanding ripples are seen to be nearly centered on the underlying thunderstorm. See text for description of the mapping projection used.

gravity wave signatures we seek. When the $30 \mathrm{~s}$ images are viewed as a video sequence, these elliptical features exhibit a distinctive outward propagation pattern originating from a well-defined center. Unlike prior observations of such concentric wave structures (Taylor and Hapgood, 1988; Dewan et al., 1998), the concentric wave patterns here are unusual in that they form complete $360^{\circ}$ closed rings. The reason for this surprising difference will become clear in Section 5.2.3.

The gravity wave structure shown in Fig. 3 may be mapped onto a flat surface to determine the relationship of the various features in the figure to the underlying thunderstorm. We projected each pixel in the image onto the $85 \mathrm{~km}$ tangent plane assuming the analysis strip (see Section 5.2.1 below) lies in the tangent plane. Fig. 4 shows the resultant map from Fig. 3 laid over the corresponding GOES weather map of the Nebraska storm. This projection clearly associates the gravity wave modulation structures with the underlying thunderstorm.

\section{Analysis}

\subsection{Identification of $\mathrm{OH}$ Meinel emissions}

The video sequence shows circular waves radiating outward from a region centered over the thunderstorm in eastern Nebraska. We interpret these propagating waves as being mesospheric nightglow emissions modulated by gravity waves generated by the underlying thunderstorm.
There are several nightglow layers in the mesosphere that are candidate sources for the observed emissions. Only two fall within our pass band. The 700-900 nm $\mathrm{OH}\left(X^{2} \Pi, \Delta v=3,4,5\right)$ Meinel sequences indicated in Fig. 1 emit from a thin layer centered at an altitude of $\sim 85 \mathrm{~km}$. The $\mathrm{O}_{2}$ Atmospheric Bands $\mathrm{O}_{2}\left(b^{1} \Sigma_{g}^{+} \rightarrow X^{3} \Sigma_{g}^{-}\right)(0-0,1)$ fall within our pass band, but the atmosphere is optically thick for the $(0,0)$ component of these emissions at $761.9 \mathrm{~nm}$ and it is therefore not observed at the ground. The brightness of the $(0,1)$ emissions at $859.8 \mathrm{~nm}$ is typically $\sim 300 \mathrm{R}$ (Slanger et al., 2000), and therefore substantially weaker than the intensities $I \sim 1 \mathrm{k} R$ detected here (see Section 5.4.1 below). The remaining two nightglow sources, the Infrared Atmospheric Bands $\mathrm{O}_{2}\left(a^{1} \Delta_{g} \rightarrow\right.$ $\left.X^{3} \Sigma_{g}^{-}, \Delta v=1\right)+h v(1.5 \mu \mathrm{m})$ and the neutral sodium $\mathrm{Na}$ $\left({ }^{2} \mathrm{P}_{1 / 2,3 / 2}^{\circ} \rightarrow{ }^{1} \mathrm{~S}_{1 / 2}\right)+h v(589 \mathrm{~nm})$ D-line emissions, fall outside the instrument pass band. We conclude that the observed emissions are most likely to be predominantly from the $\mathrm{OH}$ Meinel bands.

\subsection{Characterization of gravity wave parameters}

\subsubsection{Analysis method}

To determine the phase speed and wavelength of the outwardly expanding ripples, we established a horizontal analysis strip across the center of the ripple pattern in the image, indicated by a set of horizontal dashed lines passing through the center of the circular ripple patterns in Fig. 3. For each column the intensity was summed across 4 rows of the strip to produce a horizontal emission profile. By assuming the emissions originate at an altitude of $85 \mathrm{~km}$ corresponding to the $\mathrm{OH}$ layer, this could be converted to the corresponding horizontal emission profile as a function of transverse distance in $\mathrm{km}$. One such profile was computed for each $30 \mathrm{~s}$ image during the observing interval.

Fig. 5 shows the results of stacking horizontal emission profiles from successive images into a color-coded position-time plot, where the horizontal scale is the distance in $\mathrm{km}$ from the left edge of the image at the position of the dashed lines in Fig. 3. Time runs vertically from bottom to top beginning at 0400 UT. The outward propagation of the waves from the central region of the figure with increasing time is clearly discernible in this plot. The short upward streaks in the plot are stars as they pass through the (fixed) analysis strip. Sprites intersecting the analysis strip produce signatures of short horizontal strips of width equal the width of the sprite. However, not every sprite that was captured in the images intersected the analysis strip, so the number of sprite signatures seen here undercounts the actual number observed of approximately twenty.

\subsubsection{Wave period and horizontal wavelength}

The wave period and horizontal wavelength may be read directly from Fig. 5, and are approximately $\tau \approx 8-11 \mathrm{~min}$ and $\lambda_{\mathrm{h}} \approx 40 \mathrm{~km}$, respectively, at $1 \mathrm{~h}$ into the plot. The 


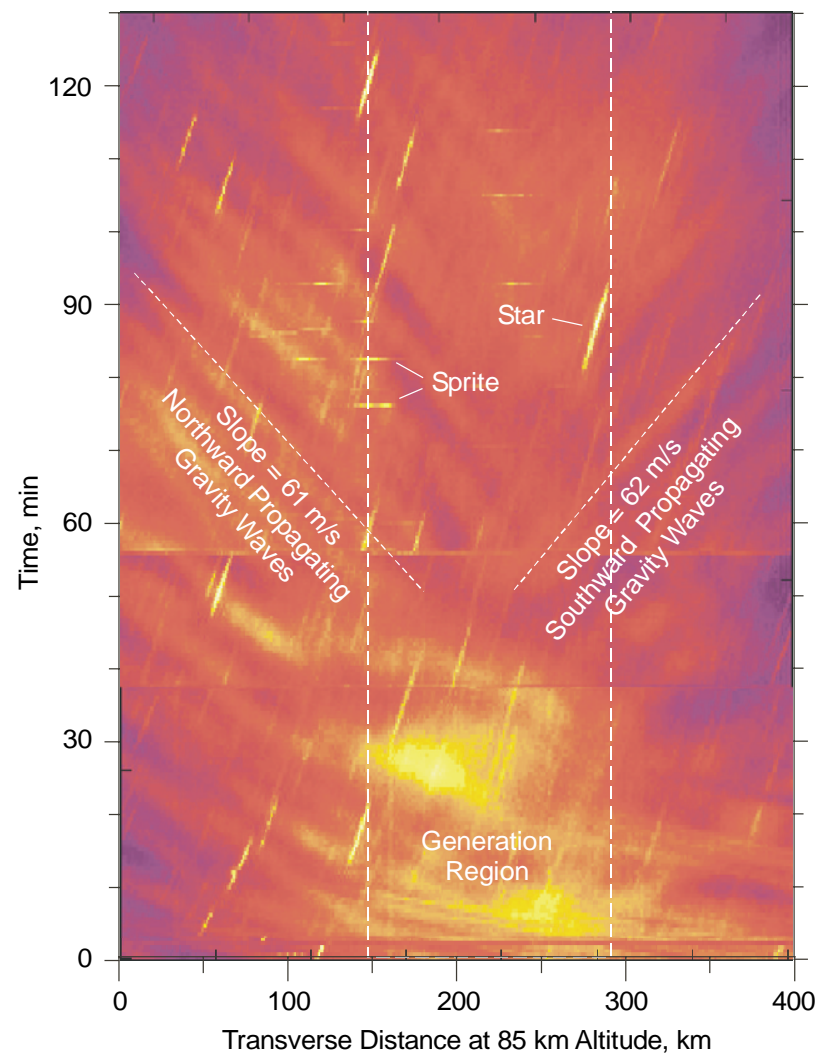

Fig. 5. Color-coded position-time plot of emission intensity along the horizontal analysis strip indicated in Fig. 2. The color axis runs through purple-red-yellow with increasing intensity. The waves appear to propagate outward and upward from the central vertical region of the figure. The wavelengths and periods of the waves are readily discernible from this plot, yielding a phase speed of about $60 \mathrm{~m} / \mathrm{s}$. The right-to-left drift of the bright (yellow) central region with increasing time tracks the movement of the underlying thunderstorm across Nebraska. Stars and sprites that appear within the analysis strip are labeled.

corresponding phase speed is $60-70 \mathrm{~m} / \mathrm{s}$. This period and wavelength differ from the periods of 5-13 min and wavelengths of $14-25 \mathrm{~km}$ previously reported by Taylor and Hill (1991), but the phase speed is comparable. In Section 5.2.4 below we analyze the time evolution of the propagation parameters that is evident in Fig. 5.

\subsubsection{Vertical wavelength}

The horizontal component $c_{\mathrm{ph}}$ of phase velocity $\mathbf{c}_{\mathrm{p}}$ is measured to be $c_{\mathrm{ph}} \approx 60 \mathrm{~m} / \mathrm{s}$ and horizontal wavelength $\lambda_{\mathrm{h}} \approx 40 \mathrm{~km}$. These results assume emissions from an altitude of $85 \mathrm{~km}$. The resulting period $\tau$ is $670 \mathrm{~s}$, or $11 \mathrm{~min}$.

From this information and the dispersion relation for gravity waves, one can infer other characteristics of the waves including the vertical wavelength $\lambda_{z}$. Gravity waves originating in the lower atmosphere propagate upward with a group velocity $\mathbf{c}_{\mathbf{g}}$ which is orthogonal to the phase velocity $\mathbf{c}_{\mathbf{p}}$, or the wave vector $\mathbf{k}=\left(k_{\mathrm{h}}, k_{z}\right)=\left(2 \pi / \lambda_{\mathrm{h}}, 2 \pi / \lambda_{z}\right)$, where $k_{\mathrm{h}}$ and $k_{z}$ are the horizontal and vertical wave numbers, and $\lambda_{\mathrm{h}}$ and $\lambda_{z}$ are the corresponding wavelengths. Hence, $\mathbf{c}_{\mathrm{g}}$ is directed along the phase fronts, and the angle of elevation $\varphi$ of the group velocity is given by

$\tan \varphi=-\frac{k_{\mathrm{h}}}{k_{z}}$.

Short-period waves for which $c_{\mathrm{ph}} \ll c_{\mathrm{s}}$, the speed of sound, satisfy the dispersion relation

$\frac{N^{2}}{\omega^{2}}-1=\frac{k_{z}^{2}}{k_{\mathrm{h}}^{2}}=\cot ^{2} \varphi$,

where $N$ is the Brunt-Vaisala frequency and $\omega=2 \pi / \tau$ is the gravity wave frequency. It follows that:

$\tan \varphi=\left(\frac{\tau^{2}}{\tau_{\mathrm{B}}^{2}}-1\right)^{-1 / 2}$.

Assuming a Brunt period $\tau_{\mathrm{B}}=2 \pi / N \approx 5 \mathrm{~min}$ and using Eq. (3), expression (5) yields

$\tan \varphi=\frac{\lambda_{z}}{\lambda_{\mathrm{h}}}=0.51$,

with the result that $\varphi=27^{\circ}$ and $\lambda_{z}=20 \mathrm{~km}$.

Assuming the emissions originate in the $\mathrm{OH}$ Meinel bands, the vertical thickness $H$ of the emission layer is roughly $8 \mathrm{~km}$ (cf. Makhlouf et al., 1995). Hence, the phase 
of the wave changes very little in the $z$ direction across the layer $\left(H \lesssim \lambda_{z} / 2\right)$, and one would expect to have little "observational filtering" of the wave modulation by destructive interference or cancellation effects of emissions originating from different portions of the emitting layer. This is consistent with the observed gross spatial structure of the gravity wave emissions, where there is little variation in the modulation amplitude across the entire structure. The large vertical wavelength compared to $H$ is the reason why the concentric wave fronts form complete closed patterns, unlike the prior observations. By way of contrast, if the vertical wavelength $\lambda_{z}$ is less than $H$, the portions of the pattern where the line-of-sight was aligned more closely with the wave fronts would be brighter (Alexander and Picard, 1999). Such a thunderstorm-generated wave pattern with varying contrast can be seen in the MSX satellite observations of stratospheric gravity waves in $4.3-\mu \mathrm{m} \mathrm{CO}$ emission (Dewan et al., 1998). There, however, the effective thickness of the emitting layer is much greater (15$20 \mathrm{~km}$ ) (Picard et al., 1998).

\subsubsection{Time evolution}

Over the observation interval the horizontal phase speed of the waves very clearly diminishes, as shown in Fig. 5. At times near $70 \mathrm{~min}$ the slopes marked in this figure indicate a phase velocity $c_{\mathrm{ph}}$ of about $60 \mathrm{~m} / \mathrm{s}$, corresponding to a horizontal wavelength $\lambda_{\mathrm{h}} \sim 40 \mathrm{~km}$ and a period $\tau=11 \mathrm{~min}$. However, at the bottom of this figure, near the beginning of the analysis interval at $\sim 10 \mathrm{~min}$ or less, the slope is flatter, indicating a phase velocity of about $85 \mathrm{~m} / \mathrm{s}$ and a horizontal wavelength of about $50 \mathrm{~km}$. Using $\tau=\lambda_{\mathrm{h}} / c_{\mathrm{ph}}$ we obtain $\tau \approx 9.8 \mathrm{~min}$; thus both wave frequency and wavelength were higher in the earlier part of the storm. Using Eqs. (5) and (6) we can calculate $\lambda_{z}$ from the values of $\lambda_{\mathrm{h}}$ and $c_{\mathrm{ph}}$. For the early time we find $\lambda_{z}=30 \mathrm{~km}$. This is in contrast to the value $\lambda_{z}=20 \mathrm{~km}$ that is found for the later time. In Table 2 we summarize these parameters and compare them with previous results reported by Taylor and Hapgood (1988) and results obtained from MSX observations on two different days (Dewan et al., 1998).

Wavelength parameters have been related to the physical properties of thunderstorms by Alexander et al. (1995) and Pandya and Alexander (1999). The period $\tau$ is the period of mechanical oscillation of the thunderstorm, i.e. the period of the oscillating convective updrafts and downdrafts within the storm that impinge upon the tropopause. The value of $\lambda_{z}$ was shown by Salby and Garcia (1987) to be determined by the characteristic vertical dimension of $\sim 10 \mathrm{~km}$ thickness of the thunderstorm's thermal forcing layer in the troposphere. In fact the vertical extent of the storm should correspond to a half wavelength $\lambda_{z} / 2$, but in propagating from the troposphere to the stratosphere the vertical wavelength shortens by about a factor of 2 due to wave refraction (Alexander et al., 1995), so that $\lambda_{z}$ in the stratosphere and above is on the order of the vertical extent of the storm. On the basis of these considerations we see from Table 2 that the oscillation frequency and vertical extent of the storm both decrease in time during the life of the storm. The values of 20 and $30 \mathrm{~km}$ inferred from the observations appear to be too large to represent actual storm extents, but the expected qualitative evolution of the thunderstorm parameters, consisting of slowing of the mechanical oscillation and shrinking of the storm's vertical dimension, seems to be firmly established by the present measurements. Additional wavelength stretching due to wave refraction occurring when the wave propagates into the less stable mesosphere may account for a portion of the discrepancy.

\subsection{Other wave characteristics}

From the wave propagation elevation angle $\varphi$, the ground range between the source and the region where the wave pattern is observed in the nightglow may be determined. If we assume rectilinear propagation without refraction from wind shears, for a thunderstorm source altitude of $15 \mathrm{~km}$ near the tropopause and an $\mathrm{OH}$ emission altitude of $85 \mathrm{~km}$ the ground range is $70 \mathrm{~km} / 0.51 \approx 140 \mathrm{~km}$. As can be seen in Fig. 3 this corresponds roughly to the radius of the observed wave pattern, so the characteristic horizontal scale size of the gravity wave effects is on the order of a few times the height of the nightglow layer above the thunderstorm source.

The transit time from the source to the altitude where the effects are observed may be estimated to be approximately $70 \mathrm{~km} / c_{\mathrm{g} z}$, where $c_{\mathrm{g} z}$ is the vertical component of the group velocity of the gravity wave, given by $c_{\mathrm{g} z} \equiv$ $\partial \omega / \partial k_{z}=\left(\lambda_{z} / \tau\right) \cos ^{2} \phi$, where $\omega=2 \pi / \tau$ is the wave frequency (Dewan et al., 1998). Substituting the current values of the wave parameters, we calculate the vertical transit time from the thunderstorm to the mesopause $\mathrm{OH}$ layer to be approximately $40-50 \mathrm{~min}$. Hence, in comparing thunderstorm characteristics and gravity wave parameters, storms that can act as sources should be determined by looking at GOES images 40-50 min before the wave observation.

Over the observation interval the underlying thunderstorm moved at a speed of approximately $15-20 \mathrm{~m} / \mathrm{s}$, roughly $0.2-0.3$ the horizontal phase speed of the gravity waves. The region of the nightglow layer lying directly above the thunderstorm source moves with the thunderstorm, which from Fig. 3 is seen to be predominantly from right-to-left as observed from Bear Mt. looking southeastward. This movement of the thunderstorm gravity source is reflected in the nightglow modulations, which can be seen in Fig. 5 as a right-to-left drift in the brightest portion of the emissions as time progresses from bottom-to-top.

\subsection{OH brightness perturbations and associated temperature perturbations}

\subsubsection{Gravity waves}

Absolute intensity calibrations were not available for the Photometrics camera, but the intensities of the $\mathrm{OH}$ 
Table 2

Comparison of reported gravity wave parameters

\begin{tabular}{lllllllll}
\hline & $\lambda_{\mathrm{h}}(\mathrm{km})$ & $\lambda_{z}(\mathrm{~km})$ & $\tau(\mathrm{min})$ & $c_{\mathrm{ph}}(\mathrm{m} / \mathrm{s})$ & $c_{\mathrm{gh}}(\mathrm{m} / \mathrm{s})$ & $c_{\mathrm{g} z}(\mathrm{~m} / \mathrm{s})$ & $\Delta t(\mathrm{~min})$ & $\varphi(\mathrm{deg})$ \\
\hline Before 0430 & 50 & 30 & 10 & 85 & 58 & 27 & 43 & 31 \\
After 0500 & 40 & 20 & 11 & 61 & 48 & 24 & 49 & 27 \\
MSX 11/13 & 25 & 16 & 9 & 46 & 32 & 21 & 55 & 33 \\
MSX 10/2 & 50 & 18 & 15 & 56 & 50 & 18 & 64 & 20 \\
T\& H 1988 & 26 & 7 & 17 & 38 & 23 & 11 & 105 & 15 \\
\hline
\end{tabular}

$\lambda_{\mathrm{h}}$ : Horizontal wavelength.

$\lambda_{z}$ : Vertical wavelength.

$\tau$ : Wave period.

$c_{\mathrm{ph}}$ : Wave horizontal phase speed.

$c_{\text {gh }}$ : Wave horizontal group speed.

$c_{g z}$ : Wave vertical group speed.

$\Delta t$ : Wave-energy propagation time from 15 to $85 \mathrm{~km}$ altitude.

$\varphi$ : Elevation angle of group-velocity vector.

emissions may be estimated from the brightness of the sprites simultaneously recorded with the broad band, high speed imager operated during the Sprites99 campaign (Stenbaek-Nielsen et al., 2000). Sprites typically persist for a few $(\sim 3-10 \mathrm{~ms})$ and strongly saturate the 3 MR limit of the ICCD. The large sprites observed during this storm are estimated to possess brightness $\sim 10 \mathrm{MR}$. The images obtained with the Photometrics NIR CCD register the apparent nightglow brightness to be approximately one-half that of the sprites. By taking into account the sprite duration $(\sim 5 \mathrm{~ms}$ is a typical value) and the image integration time (25 s), the brightness of the gravity wave modulated $\mathrm{OH}$ emissions is estimated to be $\left(\frac{1}{2}\right)(5 \mathrm{~ms} / 25 \mathrm{~s})(10 \mathrm{MR}) \sim 1 \mathrm{kR}$. This brightness is comparable to the $\mathrm{OH}$ brightness of 1-2 kR over a similar wavelength pass band reported by Yee et al. (1991) for observations made during the ALOHA-90 campaign. We shall henceforth use $1 \mathrm{kR}$ for the mean brightness of the $\mathrm{OH}$ nightglow in our observations, recognizing that this is an approximate figure.

The optical modulation amplitude of the outwardly expanding waves was measured to be approximately $30 \%$ peak to peak compared to the background mean emission intensity. From Eq. (2) and using values of the phase speed given in Table 2, we estimate $\eta \approx 7$. The resultant temperature perturbation associated with the concentrically expanding waves is $\sim 4 \%$ of the ambient, or $\sim 7 \mathrm{~K}$.

\subsubsection{Inferred upper limit for energy deposited by sprites in the $\mathrm{OH}$ layer}

The expected emission signature of a localized transient temperature perturbation in the nightglow layer that significantly alters the $\mathrm{OH}$ emissivity is a pulse that spreads radially outward from the source at the acoustic speed. We examined the observations carefully for the occurrence of small, radially expanding ripples originating from the point where sprites penetrated the $\mathrm{OH}$ nightglow layer. In Fig. 5 they would be expected to appear as upward-slanting "wings" originating from each sprite that fell within the analysis strip. No sprite signatures of this type were detected in the $\mathrm{OH}$ emissions at the level of $2 \%$ of the background at that location. Using an assumed $\mathrm{OH}$ brightness of $\sim 1 \mathrm{kR}$ this negative result permits us to establish an observational upper limit of $\sim 20 \mathrm{R}$ for the brightness perturbation in the $\mathrm{OH}$ produced by a large sprite at altitudes $\sim 85 \mathrm{~km}$. From Eq. (2) et seq. and using values of the wave period and phase speed given in Table 2, we estimate $\eta \approx 7$. The corresponding brightness perturbation $\Delta I / I \lesssim 2 \%$ translates to an upper limit for the corresponding neutral temperature perturbation $\Delta T / T \lesssim 0.003$, or $\Delta T \lesssim 0.5 \mathrm{~K}$ at the altitude of the mesopause.

The upper limit $\Delta T<0.5 \mathrm{~K}$ for the temperature perturbation may be converted to an upper limit for the thermal energy deposited into the local medium by the sprite. If we assume that most of the energy associated with electron impact excitation is ultimately transferred into thermal energy by collisions with neutrals, then the total energy associated with this process may be estimated as $\Delta E \approx N_{\mathrm{n}} k_{\mathrm{B}} V \Delta T$, where $N_{\mathrm{n}}$ is the number density of neutrals, $k_{\mathrm{B}}=1.38 \times 10^{-23} \mathrm{~J} / \mathrm{K}$ is Boltzmann's constant, and $V$ is the effective volume of the portion of the sprite intersecting the $\mathrm{OH}$ layer. This volume is estimated using the vertical thickness $\sim 7 \mathrm{~km}$ of the $\mathrm{OH}$ emission layer and a horizontal cross section of $10^{8} \mathrm{~m}^{2}$ of the sprite where it penetrates the $\mathrm{OH}$ layer, yielding $V \sim 7 \times 10^{11} \mathrm{~m}^{3}$. With neutral density $N_{\mathrm{n}}=2 \times 10^{20} / \mathrm{m}^{3}$ at an altitude of $85 \mathrm{~km}$ and $\Delta T<0.5 \mathrm{~K}$, we arrive at an upper limit $\Delta E<1 \mathrm{GJ}$ for the associated total thermal energy deposited in the $\mathrm{OH}$ layer. As will be shown in the next section, this upper limit is very much greater than the characteristic energies deposited by sprites in this region. 


\subsubsection{Estimate of total energy deposited by sprites into the mesosphere}

To estimate the total energy deposited by the large sprites observed in association with the thunderstorm studied here we use the method presented by Heavner et al. (2000), with parameters adapted to the present problem. The method derives from estimates of total optical energy and electron temperature, and scales the problem to include contributions from unobserved infrared emissions, quenching, and inelastic collision effects from $\mathrm{N}_{2}$. The optical energy in the present case may be estimated from the total brightness and cross-section of the sprite, and the duration of the optical emissions. The brightness $B(\mathrm{R})$ in Rayleighs is given by (Chamberlain, 1961, Appendix II) $B(\mathrm{R})=10^{-6} \int_{\text {path }} F(r) \mathrm{d} r$, where the integral is taken along the line of sight through the source, and where $F(r)$ is the volume emission rate. For a brightness of $10 \mathrm{MR}$, cross-section of $(10 \mathrm{~km})^{2}$, and duration $3 \mathrm{~ms}$ we obtain a total number of photons $3 \times 10^{22}$ emitted by the sprite in the imager pass band. Assuming an average photon wavelength $\sim 800 \mathrm{~nm} \sim 1.5 \mathrm{eV}$ for the observed photons, the total optical energy emitted is $4.5 \times 10^{22} \mathrm{eV} \sim 7.5 \mathrm{~kJ}$. Using the most recent estimates for the average electron energy $\sim 2 \mathrm{eV}$ (Morrill et al., 2002) and $\mathrm{N}_{2}$ vibrational distributions (Bucsela et al., 2003), this results in an estimated upper limit of $\sim 3.3 \mathrm{MJ}$ for the total energy. It should be noted that this method of determining total energy based on optical brightness is very sensitively dependent on electron temperature when it is much less than $2 \mathrm{eV}$ and should be used with caution in this regime.

The estimate of $\sim 3.3 \mathrm{MJ}$ for the total energy compares favorably with the total energy of $\sim 2 \mathrm{MJ}$ independently estimated by Armstrong et al. (2001) based on a comprehensive model calculation for sprites of similar size and brightness. It is also of the same order of magnitude as the total electrostatic energy available in the transient electric field following a large lightning discharge. This latter may be estimated from $W=\varepsilon_{0} E^{2} V / 2$, where $\varepsilon_{0}=8.86 \times 10^{-12} \mathrm{~F} / \mathrm{m}$ is the permittivity of free space, $E$ is the amplitude of the transient electric field, and $V$ is the volume of the sprite. Using $E \sim 300 \mathrm{~V} / \mathrm{m}$ at $75 \mathrm{~km}$ (Pasko et al., 1997a) and assuming a volume $V=10^{12} \mathrm{~m}^{3}$ we obtain $W \sim 800 \mathrm{~kJ}$. The range of values $800 \mathrm{~kJ}-3.3 \mathrm{MJ}$ reflects differences in model assumptions, as well as uncertainties in the brightness/size distributions of sprites, but are consistent enough at the level of order of magnitude to suggest a characteristic energy of $\sim 1$ MJ for large, bright sprites. The uncertainty factor associated with this value remains substantial owing to the wide variety of assumptions used in the estimates, so the estimate is probably no better than order of magnitude. However, even taking into account model uncertainties this is significantly below previous upper limit estimates of $\sim 1$ GJ total energy in sprites (e.g., Heavner et al., 2000; Sentman et al., 2002), so characteristic energy estimates should be revised downward to the current order of magnitude estimate of $\sim 1-10 \mathrm{MJ}$.

\section{Discussion}

The characteristic total energy $\sim 1-10 \mathrm{MJ}$ of a sprite estimated above is clearly much smaller than the estimated upper limit $\sim 1$ GJ needed to produce a detectable response in the $\mathrm{OH}$ brightness using the reactions $(1)$ and $\left(1^{\prime}\right)$. If we further assume that local dissipation of sprite energy takes place near the $\sim 75 \mathrm{~km}$ altitude region of brightest optical emissions, then only some fraction of the total energy will be deposited in the higher $\mathrm{OH}$ layer at $\sim 85 \mathrm{~km}$, thus further widening this difference. The size of the discrepancy between the required and available energy appears to effectively rule out electrical effects associated with sprites playing a significant role in $\mathrm{OH}$ airglow processes by means of localized thermal heating alone.

One may speculate that other mechanisms could produce a signature. Here, we have assumed the source mechanism for impulsive sprite production of acoustic waves is localized Joule heating within the sprite volume. The expected effect was the launching of transient pulses or wave packets from the sprite source where it penetrated the $\mathrm{OH}$ airglow layer, and the expected signature was modulation of the temperature and the ambient $\mathrm{OH}$ emissions by the wave packets. Joule heating of the neutrals by quasi-electrostatic fields or induced currents in the sprite volume is the most likely mechanism for inducing localized bulk changes to the medium. However, other consequential effects might include perturbation to the airglow chemistry of nocturnal bands besides $\mathrm{OH}$ that lie within the mesopause vicinity of sprites, such as sodium or the oxygen bands, although these would be difficult to study from the ground.

Other signatures might include local spatial/temporal effects from the medium itself. We have focused here on the gravity wave signature, but one might also consider the infrasound branch of the acoustic dispersion relation and search for modulations in the optical emissions at infrasound frequencies $(\sim 0.1-1 \mathrm{~Hz})$ using ground based microbarograph measurements or HF measurements of the lower ionosphere.

\section{Conclusions}

\subsection{Principal results}

We have performed a simplified analysis on the $\mathrm{OH}$ gravity wave structures observed simultaneously with sprites to determine the basic wavelength and period parameters of the gravity waves, and to extract the corresponding temperature perturbations implied by these parameters. The absence of signatures in $\mathrm{OH}$ that could be associated with sprites was used to estimate an upper limit on the energy perturbation associated with the sprite. Separate calculation of the energy in a sprite based on optical emission intensities showed that the energy deposited by a sprite in the mesosphere is well below that required to produce a detectable perturbation in 
the $\mathrm{OH}$ emissions. Our principle results are:

1. Sprites and circular, outwardly expanding patterns of optical emissions were simultaneously observed in NIR 720-920 nm over an intense Nebraska thunderstorm on the night of 18 August 1999. The expanding circular emission patterns are interpreted as modulation of the nightglow $\mathrm{OH}\left(X^{2} \Pi, \Delta v=3,4,5\right)$ Meinel sequences at altitudes of $\sim 85 \mathrm{~km}$ by gravity waves propagating upward from the underlying thunderstorm.

2. The horizontal wavelength and period of the gravity waves underwent an evolution during the $2 \mathrm{~h}$ observing interval. During the early stages of the storm the horizontal wavelength was measured to be $50 \mathrm{~km}$ and the period was $9.8 \mathrm{~min}$, corresponding to a phase speed of $85 \mathrm{~m} / \mathrm{s}$. The vertical wavelength was determined to be $30 \mathrm{~km}$. Approximately $1 \mathrm{~h}$ later these parameters had evolved to $40 \mathrm{~km}$ wavelength, $11 \mathrm{~min}$ period, a markedly slower phase speed of $60 \mathrm{~m} / \mathrm{s}$ and a smaller vertical wavelength of $20 \mathrm{~km}$. The large vertical wavelength compared to the 7-km thickness of the $\mathrm{OH}$ emission layer results in an unusual complete concentric wave pattern being observed, free of observational filtering effects. The vertical wavelength of the gravity waves is several times the estimated vertical dimension of the convective pump of the underlying thunderstorm source, but the qualitative temporal change of wave parameters is in accord with present understanding of thunderstorm dynamics.

3. The average brightness of the $\mathrm{OH}$ layer was estimated from comparison with simultaneously observed sprites to be approximately $1 \mathrm{kR}$. The peak-to-peak modulation intensity of the gravity wave modulated $\mathrm{OH}$ emissions was approximately $30 \%$ of the mean during the most intense portion of the event. This level of modulation corresponds to an underlying neutral pressure/temperature perturbation of approximately $4 \%$ about the mean. For a mesopause temperature of $\sim 170 \mathrm{~K}$ the associated temperature perturbation is $\sim 7 \mathrm{~K}$.

4. Sprites observed coincident with the gravity wave effects produced no discernible perturbations or distinctive signatures in the $\mathrm{OH}$ emissions at the $2 \%$ brightness level. This corresponds to an upper limit in the brightness perturbation of $\sim 20 \mathrm{R}$, and an upper limit for sprite heating of $\Delta T \lesssim 0.5 \mathrm{~K}$ at the altitude of the mesopause. The corresponding total thermal energy deposition is $\Delta E<1 \mathrm{GJ}$ if uniform emission brightness is assumed within the volume of a sprite. This upper limit on the energy lies well above the total estimated energy of $\sim 1-10 \mathrm{MJ}$ deposited in the mesosphere by a sprite. The wide difference between the $\sim 1-10$ MJ characteristic total energy of bright sprites and the $\sim 1$ GJ energy required to produce a detectable optical response in $\mathrm{OH}$ emissions indicates that sprites do not produce a significant effect on mesospheric $\mathrm{OH}$ processes by means of thermal heating.

\subsection{Further comments on gravity wave observations}

While the principal motivation for undertaking the present work was to use possible gravity wave signatures in airglow as a tool to extract the energy deposition of sprites in the mesosphere, the image data set provides a valuable resource in its own right for studying the gravity waves associated with the storm of 18 August 1999. Additional analyses that are possible with this data include estimating the power in the waves and comparing it with what is available in the storm, considering the efficiency of the coupling to the atmosphere. This requires taking into account the wave-generation mechanisms. The three principal mechanisms by which storms can generate waves are [M.J. Alexander, private communication]:

(a) The "moving mountain": Shear flow over a dome of air associated with a moving convective cell, that is a "moving mountain" figuratively, can launch "mountain" waves upward.

(b) Transient pumping: This is the mechanical forcing effect on the atmosphere from the body force associated with the moving expanding air in the cell. There are two limits. If the forcing is impulsive, then it contains all frequencies and will tend to generate a broad spectrum of waves. According to the dispersion relation, the waves will be segregated in direction by their frequency, with short-period waves propagating more nearly vertically and longer period waves propagating in a more horizontal direction. On the other hand, there is evidence that quasi-sinusoidal oscillations of the convective air column occur in thunderstorms. Such oscillations would give rise to periodic forcing and generate quasi-sinusoidal waves. These waves would be launched at an angle determined by the period of the forcing and the wave dispersion relation. We have tacitly assumed this situation above in Section 5.2, as well as in Dewan et al. (1998).

(c) Transient heat source: This is the driving term in the thermal equation from the heat release in the storm. It tends to generate waves of given vertical wavelength $\lambda_{z}$ rather than given frequency or period. The heated air column generates waves whose half-wavelength $\lambda_{z} / 2$ is equal to the overall length of the column, as discussed in Section 5.2.5.

These mechanisms all operate simultaneously with varying relative contributions to the total energy input into the wave field and are all seen in the numerical simulations of convective wave generation (Alexander et al., 1995; Pandya and Alexander, 1999). For the present set of observations of concentrically expanding waves emanating from a point above a thunderstorm, the original explanation offered by Taylor and Hapgood (1988) appears to hold. In that report, the occurrence of concentric circular waves in the $\mathrm{OH}$ airglow assumed that the thunderstorm was a quasimonochromatic source of gravity waves, and evidence for this was cited in the work of Anderson (1960). Most recently, Piani et al. (2001) performed three-dimensional simulations of gravity waves generated by a large connective 
thunderstorm and obtained results in striking agreement with observations of Taylor and Hapgood (1988), Dewan et al. (1998), and the present work. Thus, the cause of the observed concentric patterns appears to be well understood.

Finally, the duration of excitation at the center of the outwardly expanding gravity wave ripples may be interpreted as being caused by periodic or quasi-periodic ringing at the tropopause due to pumping by the buoyant air column in the convective cell below. The resultant pressure pulse is transmitted through the stratosphere and mesosphere at the pump frequency. The combination of spatially concentric localization of the gravity wave signatures and their quasi-monochromatic temporal oscillations would seem to suggest a compact source at the tropopause with a characteristic pump period reflecting the convective column dynamics. The long duration of the gravity wave signatures suggests that the source must have been at least narrow band/quasi-periodic.

\section{Acknowledgements}

This research was partially supported by NASA Grants NAG5-5019 and NAG5-0131 to the University of Alaska. RHP, JRW, and EMD are grateful for the support of Kent Miller of the Air Force Office of Scientific Research, and RHP acknowledges useful discussions with Joan Alexander. MJH acknowledges support from NIS-1 at Los Alamos, and JM from 6.1 funds at the Naval Research Laboratory. We thank R.A. Armstrong for discussions on the energy problem of sprites, and V.P. Pasko for useful suggestions. Special thanks are extended to the U.S. Forest Service in Custer, SD for permitting us to use the lookout tower at Bear Mountain during the Sprites99 Campaign. The observations described here were originally presented at the 1999 Fall Meeting of the American Geophysical Union (Sentman et al., 1999). The video clip exhibiting the gravity waves and sprites discussed herein is available on request from dsentman@gi.alaska.edu.

\section{References}

Alexander, M.J., Picard, R.H., 1999. Evaluating the importance of convectively generated waves observed by the MSX satellite to middle atmosphere dynamics. EOS Transactions on American Geophysical Union 80, F207.

Alexander, M.J., Holton, J.R., Durran, D.R., 1995. The gravity wave response above deep convection in a squall line simulation. Journal of Atmospheric Science 52, 2212-2226.

Anderson, C.E., 1960. Cumulus Dynamics. Pergamon Press, New York.

Armstrong, R.A., Shorter, J.A., Taylor, M.J., Suszcynsky, D.M., Lyons, W.A., Jeong, L.S., 1998. Photometric measurements in the Sprites'95 and '96 campaigns of nitrogen second positive $(399.8 \mathrm{~nm})$ and first negative $(4278 \mathrm{~nm})$ emissions. Journal of Atmospheric and Solar-Terrestrial Physics 60, 787-799.
Armstrong, R.A., Suszcynsky, D.M., Lyons, W.A., Nelson, T.E., 2000. Multi-color photometric measurements of ionization and energies in sprites. Geophysical Research Letters 27, 653-656.

Armstrong, R.A., Suszcynsky, D.M., Lyons, W.A., Williams, E.A., 2001. Optical signatures, energy deposition, ionization and chemical dynamics in lightning-induced transient electrodynamic middle and upper atmospheric events (sprites). National Union Radio Science, Boulder, CO, January (Abstract).

Bates, D.R., Nicolet, M., 1950. The photochemistry of atmospheric water vapor. Journal of Geophysical Research 55, 301.

Bering, E.A., Benbrook, J.R., Garrett, J.A., Paredes, A., Wescott, E.M., Sentman, D.D., Stenbaek-Nielsen, H.C., Lyons, W.A., 1999. The 1999 Sprites Balloon Campaign. EOS Transactions on American Geophysical Union 82, Fall Meet. Suppl. A42E-01 (Abstract).

Bering, E.A., Benbrook, J.R., Garrett, J.A., Paredes, A.M., Wescott, E.M., Moudry, D.R., Sentman, D.D., Stenbaek-Nielsen, H.C., Lyons, W.A., 2002. The electrodynamics of sprites. Geophysical Research Letters 10.1029/2001GL013267, 13 March.

Bucsela, E., Morrill, J., Siefring, C., Heavner, M., Moudry, D., Sentman, D., Wescott, E., Osborne, D., Benesch, W., 1998. Estimating electron energies in sprites from $1 \mathrm{NG} / 2 \mathrm{PG}$ intensity ratios. EOS Transactions on American Geophysical Union 81, Fall Meeting Suppl., Abstract A42-D04.

Bucsela, E., Morrill, J., Heavner, M., Siefring, C., Berg, S., Hampton, D., Moudry, D., Wescott, E., Sentman, D., 2003. $\mathrm{N}_{2}\left(B^{3} \Pi_{g}\right)$ and $\mathrm{N}_{2}^{+}\left(A^{2} \Pi_{u}\right)$ vibrational distributions observed in sprites. Journal of Atmospheric Solar-Terrestrial Physics 65 (5), 581-588.

Cartwright, D.C., 1978. Vibrational populations of the excited states of $\mathrm{N}_{2}$ under auroral conditions. Journal of Geophysical Research $83,517-531$.

Chamberlain, J.W., 1961. Physics of the Aurora and Airglow. Academic Press, New York.

Dewan, E.M., Picard, R.H., O’Neil, R.R., Gardiner, H.A., Gibson, J., Mill, J.D., Richards, E., Kendra, M., Gallery, W.O., 1998. MSX satellite observations of thunderstorm-generated gravity waves in midwave infrared images of the upper stratosphere. Geophysical Research Letters 25, 939-942.

Fukunishi, H., Takahashi, Y., Fujito, M., Watanabe, Y., Sakanoi, K., 1996. Fast imaging of elves and sprites using a framing/streak camera and a multi-anode array photometer. EOS Transactions on American Geophysical Union 77, F60.

Fukunishi, H., Takahashi, Y., Uchida, A., Sera, M., Adachi, K., Miyasato, R., 1999. Occurrences of sprites and elves above the Sea of Japan near Hokuriku in Winter. EOS Transactions on American Geophysical Union, Fall Meeting, San Francisco.

Gerken, E.A., Inan, U.S., Barrington-Leigh, C., 2000. Telescopic imaging of sprites. Geophysical Research Letters 27 (17), 2637-2640.

Green, B.D., Fraser, M.E., Rawlins, W.T., Jeong, L., Blumberg, W.A.M., Mende, S.B., Swenson, G.R., Hampton, D.L., Wescott, E.M., Sentman, D.D., 1996. Molecular excitation in sprites. Geophysical Research Letters 23, 2161-2164.

Hampton, D.L., Heavner, M.J., Wescott, E.M., Sentman, D.D., 1996. Optical spectral characteristics of sprites. Geophysical Research Letters 23, 89-92.

Heavner, M.J., Sentman, D.D., Moudry, D.R., Wescott, E.M., Siefring, C.L., Morrill, J.S., Bucsela, E.J., 2000. Sprites, blue jets, and elves: optical evidence of energy transport across the stratopause. In: Siskind, D. (Ed.), Atmospheric Science Across the Stratopause. American Geophysical Union, Washington DC. 
Krassovsky, V.I., 1972. Infrasonic variations of $\mathrm{OH}$ emission in the upper atmosphere. Annals of Geophysics 28, 739.

Lyons, W.A., 1994. Characteristics of luminous structures in the stratosphere above thunderstorms as imaged by low-light video. Geophysical Research Letters 21, 875-878.

Lyons, W.A., 1996. Sprite observations above the U.S. High Plains in relation to their parent thunderstorm systems. Journal of Geophysical Research 101, 29,641-29,652.

Makhlouf, U.B., Picard, R.H., Winick, J.R., 1995. Photochemicaldynamical modeling of the measured response of airglow to gravity waves. Journal of Geophysical Research 100, 11,28911,311 .

Meinel, A.B., 1950. OH emission bands in the spectrum of the night sky. Astrophysics Journal 111, 555.

Mende, S.B., Rairden, R.L., Swenson, G.R., 1995. Sprite spectra: $\mathrm{N}_{2}$ 1PG band identification. Geophysical Research Letters 20, 2536-2633.

Morrill, J.S., Bucsela, E.J., Pasko, V.P., Berg, S.L., Heavner, M.J., Moudry, D.R., Benesch, W.M., Wescott, E.M., Sentman, D.D., 1998. Time resolved $\mathrm{N}_{2}$ triplet state vibrational populations and emissions associated with red sprites. Journal of Atmospheric and Solar-Terrestrial Physics 60, 811-830.

Morrill, J., Bucsela, E., Siefring, C., Heavner, M., Berg, S., Moudry, D., Slinker, S., Fernsler, R., Wescott, E., Sentman, D., Osborne, D., 2002. Electron energy and electric field estimates in sprites derived from ionized and neutral $\mathrm{N}_{2}$ emissions. Geophysical Research Letters 20 (10) 100-1 to 100-4.

Moudry, D., Stenbaek-Nielsen, H., Sentman, D., Wescott, E., 2003. On sprite initiation. Journal of Atmospheric and Solar-Terrestrial Physics 65 (5), 509-518.

Pandya, R., Alexander, M.J., 1999. Linear stratospheric gravity waves above convective thermal forcing. Journal of Atmospheric Science 56, 2434-2446.

Pasko, V.P., Inan, U.S., Bell, T.F., Taranenko, Y.N., 1997a. Sprites produced by quasi-electrostatic heating and ionization in the lower ionosphere. Journal of Geophysical Research 102, 4529.

Pasko, V.P., Inan, U.S., Bell, T.F., 1997b. Sprites as evidence of vertical gravity wave structures above mesoscale thunderstorms. Geophysical Research Letters 24 (14), 1735-1738.

Pasko, V.P., Inan, U.S., Bell, T.F., 1998. Spatial structure of sprites. Geophysical Research Letters 25, 2123-2126.

Pearse, R.W.B., Gaydon, A.G., 1976. The Identification of Molecular Spectra, 4th edition. Wiley, New York.

Piani, C., Durran, D., Alexander, M.J., Holton, J.R., 2001. A numerical study of three dimensional gravity waves triggered by deep tropical convection and their role in the dynamics of Q.B.O. Journal of Atmospheric Science 57, 3689-36702.

Picard, R.H., O’Neil, R.R., Gardiner, H.A., Gibson, J., Winick, J.R., Gallery, W.O., Stair Jr., A.T., Wintersteiner, P.P., Hegblom, E.R., Richards, E., 1998. Remote sensing of discrete stratospheric gravity-wave structure at $4.3-\mu \mathrm{m}$ from the MSX satellite. Geophysical Research Letters 25, 2809-2812.

Rowland, H.L., 1998. Theories and simulations of elves, sprites and blue jets. Journal of Atmospheric and Solar-Terrestrial Physics 60, 831-844.

Rowland, H.L., Fernsler, R.F., Bernhardt, P.A., 1996. Breakdown of the neutral atmosphere in the D-region due to lightning driven electromagnetic pulses. Journal of Geophysical Research 101, 7935.

Salby, M.L., Garcia, R.R., 1987. Transient response to localized episodic heating in the tropics. Part 1: Excitation and short-time near-field behavior. Journal of Atmospheric Science 44, 458-497.

Sentman, D.D. (Ed.), 1998. Effects of Thunderstorm activity on the upper atmosphere and ionosphere. Journal of Atmospheric and Solar-Terrestrial Physics 60(7-9) (Special issue).

Sentman, D.D., Wescott, E.M., 1993. Video observations of upper atmospheric optical flashes recorded from an aircraft. Geophysical Research Letters 20, 2857-2860.

Sentman, D.D., Wescott, E.M., Osborne, D.L., Hampton, D.L., Heavner, M.J., 1995. Preliminary results from the Sprites 94 aircraft campaign: 1. Red sprites. Geophysical Research Letters $22,1205-1208$.

Sentman, D.D., Wescott, E.M., Stenbaek-Nielsen, H.C., Heavner, M.J., Moudry, D.R., São Sabbas, F.T., 1999. Observations of gravity waves associated with a sprite-producing storm. EOS Transactions on American Geophysical Union, 82(48), Fall Meet. Suppl. A12B-06 (Abstract).

Sentman, D.D., Stenbaek-Nielsen, H.C., Wescott, E.M., Heavner, M.J., Moudry, D.R., São Sabbas, F.T., 2002. Effects of lightning on the middle and upper atmosphere: some new results. In: Space Weather Study Using Multipoint Techniques, COSPAR Colloquia Series, Vol. 12, Pergamon Press, New York, pp. 267-274.

Siefring, C., Bernhardt, P., Morrill, J., Sentman, D., Wescott, E., Heavner, M., Osborne, D., Bucsela, E., 1998. Correlation between ambient Near InfraRed (NIR) airglow and sprite structures. EOS Transactions of American Geophysical Union 81, Fall Meeting Suppl., Abstract A42-D05.

Slanger, T.G., Cosby, P.C., Huestis, D.L., Osterbrock, D.E., 2000. Vibrational level distribution of $\mathrm{O}_{2}\left(b^{1} \Sigma_{g}^{+}, v=0-15\right)$ in the mesosphere and lower thermosphere region. Journal of Geophysical Research 105 (D16), 20,557-20,564.

Stenbaek-Nielsen, H.C., Moudry, D.R., Wescott, E.M., Sentman, D.D., São Sabbas, F.T., 2000. Sprites and possible mesospheric effects. Geophysical Research Letters 27, 3829-3832.

Su, H.-T., Hsu, R.R., Chen, A.B.-C., Lee, Y.-J., Lee, L.-C., 2002. Observation of sprites over the Asian continent and over oceans around Taiwan. Geophysical Research Letters, 10.1029/2001GL013737, 27 February.

Suszcynsky, D.M., Roussel-Dupré, R.A., Lyons, W.A., Armstrong, R.A., 1998. Blue light imagery and photometry of sprites. Journal of Atmospheric Solar-Terrestrial Physics 60, 801.

Swenson, B.R., Liu, A.Z., 1998. A model for calculating acoustic gravity wave energy and momentum flux in the mesosphere from $\mathrm{OH}$ airglow. Geophysical Research Letters 25, 477.

Takahashi, U., Watanabe, Y., Uchida, A., Sera, M., Sato, M., Fukunishi, H., 1998. Energy distributions of electrons exciting sprites and elves inferred from the Fast Array Photometer observations. EOS Transactions on American Geophysical Union 79, F175.

Taylor, M.J., Hapgood, M.A., 1988. Identification of a thunderstorm as a source of short period gravity waves in the upper atmospheric nightglow emissions. Planetary Space Science 36, 975-985.

Taylor, M.J., Hill, M.J., 1991. Near infrared imaging of hydroxyl wave structure over an ocean site at low latitudes. Geophysical Research Letters 18, 1333-1336.

Taylor, M.J., Turnbull, D.N., Lowe, R.P., 1991a. Coincident imaging and spectrometric observations of zenith $\mathrm{OH}$ nightglow structure. Geophysical Research Letters 18, 1349-1352.

Taylor, M.J., Espy, P.J., Baker, D.J., Sica, R.A., Neal, P.C., Pendleton Jr., W., 1991b. Simultaneous intensity temperature 
and imaging measurements of short period wave structure in the $\mathrm{OH}$ nightglow emissions. Planetary Space Science 39, 1171-1188.

Taylor, M.J., Taylor, V., Edwards, R., 1995. An investigation of thunderstorms as a source of short period mesospheric gravity waves. In: The Upper Mesosphere and Lower Thermosphere: A Review of Experiment and Theory, AGU Geophysical Monograph, Vol. 87. American Geophysical Union, Washington, DC, p. 177.
Turnbull, D.N., Lowe, R.P., 1991. Temporal variations in the hydroxyl nightglow observed during ALOHA-90. Geophysical Research Letters 18, 1345.

Yee, J.-H., Niciejewski, R., Luo, M.Z., 1991. Observations of $\mathrm{O}_{2}\left({ }^{1} \Sigma\right)$ and $\mathrm{OH}$ nightglow during the ALOHA-90 campaign. Geophysical Research Letters 18, 1357-1360. 